\title{
Incident Nephrotic Syndrome
}

National Cancer Institute

\section{Source}

National Cancer Institute. Incident Nephrotic Syndrome. NCI Thesaurus. Code C122800.

New onset nephrotic syndrome. 